\title{
Familiarity and pronounceability of nouns and names
}

\author{
AIMÉE M. SURPRENANT \\ Purdue University, West Lafayette, Indiana \\ SUSAN L. HURA \\ Lucent Technologies, Holmdel, New Jersey \\ and
}

MARY P. HARPER, LEAH H. JAMIESON, GLENIS LONG, SCOTT M. THEDE, AYASAKANTA ROUT, TSUNG-HSIANG HSUEH, STEPHEN A. HOCKEMA, MICHAEL T. JOHNSON, PRAMILA N. SRINIVASAN, CHRISTOPHER M. WHITE, and J. BRANDON LAFLEN

Purdue University, West Lafayette, Indiana

\begin{abstract}
Ratings of familiarity and pronounceability were obtained from a random sample of 199 surnames (selected from over 80,000 entries in the Purdue University phone book) and 199 nouns (from the Kučera-Francis, 1967, word database). The distributions of ratings for nouns versus names are substantially different: Nouns were rated as more familiar and easier to pronounce than surnames. Frequency and familiarity were more closely related in the proper name pool than the word pool, although both correlations were modest. Ratings of familiarity and pronounceability were highly related for both groups. A production experiment showed that rated pronounceability was highly related to the time taken to produce a name. These data confirm the common belief that there are differences in the statistical and distributional properties of words as compared to proper names. The value of using frequency and the ratings of familiarity and pronounceability for predicting variations in actual pronunciations of words and names are discussed.
\end{abstract}

Recently, there has been an explosion of research regarding how people store and access proper names. The interest has been enough to generate a special issue of the journal Memory (Cohen \& Burke, 1993) and at least one entire book on the subject (Valentine, Brennen, \& Brédart, 1996). Much of the research has concentrated on how names and faces are related and on whether names and other words are represented separately in the lexicon. The studies reported here are meant to provide a corpus of ratings of familiarity and pronounceability of surnames for use in experiments in human lexical access of names and for predicting variability in pronunciations of names for eventual use in applications such as computer speech recognizers.

\section{Proper Nouns as a Challenge for Humans}

Recognition of a printed name involves a specialized sort of lexical access, having only some features in common with other types of words. Generally, lexical access

Portions of this work were supported by the Purdue Research Foundation and an Interdisciplinary Research Grant from the Purdue University School of Liberal Arts and the Schools of Engineering awarded to A.M.S., S.L.H., L.H.J., and M.P.H. The authors thank John Steele and Scott Ksander of the Purdue University Computing Center for providing electronic access to the Purdue phone directory list of surnames. Correspondence should be addressed to A. M. Surprenant, Department of Psychological Sciences, Purdue University, West Lafayette, IN 47907 (e-mail: aimee(@)psych.purdue.edu). in reading is thought of as having two routes: phonological (sound-based) and lexical (word-based) (e.g., Coltheart, Curtis, Atkins, \& Haller, 1993). The phonological route is especially important in the case of novel words, which are likely to be read through a more bottom-up process of identifying the phonemes making up the word. The lexical route uses context, meaning, frequency, and familiarity to help access words already in the lexicon. Proper names occupy a unique position in lexical access: Although both names and words have referents (entities in the world to which the word/name refers), names have no inherent meaning (or sense in semantic terminology; Quine, 1960). Thus, in one way, names behave like new words, which require phonological processing. On the other hand, proper names have aspects of frequency and familiarity that may allow them to act like old words.

The research on the differences between memory and lexical access for proper names, relative to other nouns, shows that (1) proper names are more difficult to learn and to recall than other biographical information (Cohen \& Faulkner, 1986; Young, Ellis, \& Flude, 1988), (2) retrieval of proper names appears to decline with aging, more so than retrieval of other types of words (Burke, Mackay, Worthley, \& Wade, 1991), and (3) proper-name retrieval and recognition can be selectively impaired in aphasia (Lucchelli \& De Renzi, 1992). Prominent theories of proper-name access suggest that proper names act 
like nonwords in that they can be connected to semantic information but have no intrinsic meaning in and of themselves (Cohen, 1990). Access to the name of a person seems to be dependent on prior activation of semantic information about that person-name information is retrieved only through the semantic system and is often represented in separate units (Burton \& Bruce, 1992).

Most of the models of proper-name recognition cited above state that there is a difference between proper names and other types of nouns in their statistical characteristics (e.g., frequency and familiarity) but cite no data other than intuition to support this claim. Because models of lexical access are heavily dependent on the frequency and/or familiarity of the words (Forster, 1979; Monsell, 1991; Morton, 1969), these distributional factors must be specified in order to develop a comparable body of data on lexical access of proper names. Researchers using the ratings of word frequency and familiarity published in the literature are aware that they are very rough estimates of the actual frequency of occurrence in the lives of any particular subject in their study. However, even with that knowledge, the ratings have proven to be very useful, with a number of collections of ratings from decades ago still being cited and widely used (e.g., Kučera \& Francis, 1967; Paivio, Yuille, \& Madigan, 1968).

Unfortunately, with a few exceptions, there exists relatively little information on the distribution of proper names in the language. Whalen and Zsiga (1994) examined the differences in familiarity for word/first-name homophones. They found that frequency and familiarity were less highly related when the subjects were rating the stimuli as names than when they were rating them as words. They suggested that, if familiarity is the variable of interest, it ought to be measured directly. Zechmeister, King, Gude, and Opera-Nadi (1975) collected ratings of frequency, familiarity, orthographic distinctiveness, and pronounceability for surnames. They found that there were small correlations between the actual frequency of a name in the phone book and familiarity and pronounceability. They also found a substantial correlation between rated familiarity and pronounceability. However, Zechmeister et al. did not compare their ratings to ratings of other types of words using the same rating scale. There are a number of reasons to suppose that words and proper names will be rated differently on some or all of those measures.

\section{Proper Nouns as a Challenge for Automatic Speech Recognition (ASR)}

The automatic recognition of proper names is an important component of a very practical problem: Building an acoustic interface to a library catalog or telephone directory database (Kamm, Shamieh, \& Singhal, 1995; Lennig, Bielby, \& Massicotte, 1995; Vysotsky, 1995). Such databases pose a unique challenge because they contain a very large number of proper names, each of which may be read and pronounced in a variety of ways. A person using such a database would generally read the name from a written text and pronounce it out loud for the machine to recognize. At present, incorrect recognition of proper nouns has been cited as the principal source of word errors in automatic speech recognition systems (Deshmukh, Ngan, Hamaker, \& Picone, 1997).

When a person attempts to read and pronounce a word, top-down information (e.g., frequency, familiarity, phonology, context, etc.) help guide the pronunciation process (Levelt, 1992). Statistical models based on such information have been used fairly successfully to improve the performance of speech recognizers (e.g., Thede, 1998). Such variables as familiarity and pronounceability may be used to help predict the pronounceability of a name. Names that are rated as familiar and easy to pronounce are likely to have a much smaller range of actual pronunciations than those that are rated as unfamiliar and difficult to pronounce.

To construct better speech recognizers for proper names, it is important that we determine the parameters that predict the consistency of pronunciation for a set of names that will be read from text, as well as the variations that can be expected. It is likely that the statistical aspects of proper names (like frequency and familiarity) will be important factors for determining which names have a wide set of pronunciation variations. It is well known that, in human speech perception, words of higher frequency and familiarity are read and named faster and more efficiently than are words of lower frequency and familiarity (Howes, 1957; Newbigging, 1961; Savin, 1963; Soloman \& Postman, 1952). Therefore, a promising immediate approach to improving speech recognizer performance is to incorporate the statistical aspects of proper names directly. If we can predict that a particular name will be pronounced with little variation (on the basis of statistical aspects of that name), we can use that information to allow for only a very small range of variation in the recognition of that name. If, however, we expect that there will be multiple variations in the name, a less strict criterion for recognizing variations can be adopted. Frequency is a purely numerical measure, obtained from calculations on the database in question; familiarity and pronounceability, however, require subjective judgments from human raters.

\section{EXPERIMENT 1}

In Experiment 1, we assessed the relationship between the written frequency of words (from written frequency counts) and names (from the phone book) and subjective ratings of the familiarity and pronounceability of words and names. We also compared the ratings of our common nouns with those already available in the literature (when possible) to determine whether our population of raters was similar in experience to previous populations. In addition, we compared our name ratings to those obtained by Zechmeister et al. (1975).

There are some important considerations to be examined when choosing which items to be used in a rating study. Given the purpose of the experiment, to generalize to the whole population of nouns and names, we decided to choose both sets of stimuli by randomly sampling 
their respective databases. This had the advantage of allowing generalizability but the disadvantage of allowing the number of syllables, word length, orthographic regularity, and visual familiarity to vary between the sets of stimuli. However, had we controlled for all of those factors we would have lost just what makes names unique and a difficult problem for both human and computer name recognition.

Two other important methodological considerations are the mode of presentation of the stimuli and the knowledge given to the rater about the nature of the task. In the case of directory assistance or library databases, the user will generally request information about a name that has been read from a catalog or other print source. Thus, from the pronouncer's point of view, the statistical properties that are used to construct a pronunciation of the name will be derived from an orthographic representation of the name. In addition, the pronouncer will know that the utterance being pronounced is a name, not a regular noun, and will use that knowledge to aid in the pronunciation of the name. In the lexical access of name literature, names are almost always presented in written form, and the subjects are very much aware that these are names instead of common nouns. Thus, we decided to present the names in written form and to block the ratings by common nouns and names so that all of the stimuli within a block were from the same category. We did counterbalance order of rating nouns and names across subjects to determine whether there was a carryover effect of rating nouns before names, or vice versa.

\section{Method}

\section{Stimuli}

Surname pool. Two hundred surnames were selected at random from the 29,928 distinct names in the Purdue University phone book. Purdue University is a large, Midwestern university with approximately 33,000 undergraduate students. Hyphenated names, if chosen, were excluded, and a new name was chosen at random. One name was discarded due to an error, leaving 199 names for analysis. The frequency ranged from 1 to 107 occurrences. Mean frequency of our stimulus set was 3.7 , with a median of 1 and a standard deviation of 10.6 .

Word pool. Two hundred common nouns were chosen at random from the Penn-Treebank corpus (Marcus, Santorinin, \& Marcinkiewicz, 1993), which is a subset of the Kucera-Francis corpus of written English words (Kučera \& Francis, 1967). One word was discarded after the experiment because it was an abbreviation, leaving 199 words for the data analysis. The frequency of occurrence of our stimulus set ranged from 1 to 25 , with a mean of 2 and a standard deviation of 3.5. The distribution of frequency in nouns is more normal and somewhat less skewed than the names.

\section{Subjects}

Seventy-five Purdue University undergraduates participated in the familiarity rating portion of the experiment for course credit. Twelve subjects were discarded because they were nonnative or bilingual speakers of American English or because they failed to follow instructions, leaving 63 subjects who rated the names and nouns for familiarity. Fifty different students from the same pool rated nouns and names on pronounceability. Two of these were discarded for failure to follow instructions and 4 were discarded for being non- native English speakers, leaving 44 subjects in the pronounceability segment and a total of 107 subjects in the whole experiment.

\section{Procedure for the Familiarity Rating}

For the familiarity ratings, the subjects were tested in two groups of approximately 35 , with the first group rating the names first followed by the nouns and the other group receiving the two pools in opposite order. All subjects first filled out a dialect questionnaire that asked broad questions about places of residence and familiarity with foreign languages. The questionnaire was designed to provide basic dialect information that might affect the subjects' responses to the surname stimuli.

Each subject was given a packet of scantron sheets, a pencil, and a sheet with instructions. The instructions were changed depending on the condition, with the instructions for the proper-name condition in parentheses:

You are about to see a list of English words (names). What we want to know is how familiar that word (name) is to you. We would like you to judge each word (name) for familiarity, which is how commonly or frequently the words (names) have been experienced by you or how familiar they appear to be. If you think the word (name) you see is one that you have ENCOUNTERED VERY FREQUENTLY, fill in the circle marked 7 . If you think that it is one that you have NOT ENCOUNTERED FREQUENTLY, fill in the $l$. For example, you probably encounter the word "class" (name "Smith") very frequently in your everyday life. You would probably fill in the circle marked 6 or 7 for that word (name). However, you probably encounter the word "rutabaga" (name "Hura") very infrequently and so that word (name) would receive a 1 or 2 . Try to use all the values in between, since many items fall between these extremes. At the beginning, you may not be too sure about where you are on the scale, but don't worry about it, just put down your first impression and leave it. There are no right or wrong answers so please do not go back and change any of your answers. Even if you have to guess do not leave any blanks. In case you forget, the rating scale will be left on the screen for the entire experiment so you can look at it at any time.

There will be 10 practice words (names) in order to give you a feel for the pacing of the experiment. The words (names) will have $7 \mathrm{sec}-$ onds between them and a computer beep will signal that the next word (name) is coming. There is a longer pause at the end of each group of 20 which will help you keep your place.

Any questions?

Words (either nouns or names) were presented one at a time, projected on an overhead screen. There were 10 practice trials before each section, and the subjects were allowed to take a break between each group of ratings. Each word was presented for $7 \mathrm{sec}$, and a computer beep signaled the presentation of a new item. Each stimulus was rated on a scale of 1-7, with 1 meaning not familiar and 7 indicating very familiar. At the end of the session, the subjects were debriefed and thanked.

\section{Procedure for the Pronounceability Ratings}

Data for the pronounceability ratings were collected in three separate sessions. Each subject was given 199 words and 199 names to rate on a scale of $1-7$, with 1 being very difficult to pronounce and 7 being very easy to pronounce. Two different random orders of words and names were constructed (Forms 1 and 2), and half of the subjects in each session were given each form. In addition, order of noun or name rating was counterbalanced across subjects. As a final manipulation check, the subjects were given 50 of the words or names in a new random order at the end of the experiment and asked to rerate them. Each subject was given a packet of pages including the following instructions:

On the following pages are lists of nouns and last names. What we would like you to do is to decide how difficult it would be for you to pronounce the names and nouns on a scale of $1-7$. If you think it is very difficult to pronounce, please circle the $i$ next to the name or noun. If it is an easy name or noun for you to pronounce, circle the 7 next to the 
name or noun. If it is in the middle, circle 4 next to the name or noun. Please try to use the entire scale to make your decision. Also please make a decision for each noun or name

There are no right or wrong answers - don't go back to change any of the nouns or names you have already rated. Please feel free to take a break whenever you wish.

Any questions?

The subjects were allowed to go at their own pace but were instructed not to go back and change ratings they had already made.

\section{Results and Discussion}

Results from the dialect questionnaire showed that, of the 107 native monolingual speakers of American English whose data were included in this experiment, a large majority (74) were speakers of an Indiana dialect. These subjects reported living the majority of their lives in Indiana, often in the same town for their whole life. Of the remaining subjects, 6 spoke a Chicago dialect, 14 spoke other Midwestern dialects (primarily Ohio, Pennsylvania, Michigan, and Wisconsin), and 5 spoke an East Coast dialect. Only 8 subjects reported living in numerous $(>4)$ different regions of the United States and were unsure how to classify their dialects.

Appendix A shows the frequency count (from the $\mathrm{Ku}$ čera \& Francis, 1967, database), familiarity ratings, and pronounceability ratings (along with the standard deviation) for the nouns used in this study. Appendix B shows the actual frequency in the Purdue phone book for each name that we used and the ratings of surname familiarity and pronounceability obtained from our subjects (along with the standard deviation).

Correlations between the two familiarity rating sessions were .94 and .90 (both $p s<.05$ ) for nouns and names, respectively. Thus, order effects were inconsequential, and the rest of the results were collapsed across the two sessions. Correlations among sessions and forms for the pronounceability ratings of the names were all greater than .9 (all $p \mathrm{~s}<.01)$, so order and form effects were negligible. However, the correlations among forms and sessions for the words were much lower, ranging from .8 $(p<.01)$ to $.5(p<.05)$. Scatterplots revealed that these correlations were due to a ceiling effect: The subjects rarely used a rating of less than 5 (easy to pronounce) on the words. Only nine words (comradeship, epicure, acreage, filibusters, ouster, reprisals, appeasement, inadequacy, and acquaintance) were given an average rating of less than 6 , as opposed to 138 names in the name pool.

The 50 names and nouns presented in the retest correlated .86 for names and .74 for nouns (both $p s<.01$ ), indicating that the subjects were fairly consistent when asked to rerate the names and nouns for pronounceability.

Table 1 shows the distributions of familiarity and ratings for the names and nouns. Note that the distributions are very different, with nouns being, on the whole, much more familiar than names $\left[F(1,62)=319.81, M S_{\mathrm{e}}=0.66, p<\right.$ $.05]$. The most common response for names (mode) was a 1 (not familiar at all), with a mean of 2.33 , a median of 1.47 , and a standard deviation of 1.08 . The mode for nouns was a 7 (very familiar), with a mean of 4.90 , a median of
Table 1

Percentage of Responses at Each Familiarity Rating for Names and Nouns

\begin{tabular}{|c|c|c|c|c|c|c|c|}
\hline & $\begin{array}{c}\text { Not familiar } \\
\text { at all } \\
1\end{array}$ & 2 & 3 & 4 & 5 & 6 & $\begin{array}{c}\text { Very } \\
\text { familiar } \\
7\end{array}$ \\
\hline Names & 51.1 & 16.4 & 10.4 & 7.3 & 5.8 & 4.3 & 4.8 \\
\hline Nouns & 4.0 & 8.3 & 12.0 & 14.5 & 17.6 & 17.5 & 26.0 \\
\hline
\end{tabular}

4.69 , and a standard deviation of 0.90 . Table 2 shows the distribution of pronounceability ratings for the names and nouns. The distributions are also very different, with nouns being rated, on the whole, as much easier to pronounce than names, although this difference between nouns and names was not as striking as in the familiarity ratings $[F(1,43)=$ 116.16, $\left.M S_{\mathrm{e}}=0.31, p<.05\right]$. The most common response for names (mode) was 7, with a mean of 5.34, a median of 6.25 , and a standard deviation of 1.89 . The modal response for words was also 7, but the mean and medians were higher (6.56 and 6.84, respectively) and the standard deviation for the words was lower than for the names (0.92).

Table 3 shows the correlations between the present familiarity and pronounceability ratings for nouns with some other ratings available in the literature. We were interested in how similar our ratings were to some often-cited ratings of words. Some of our words were not present in some of the corpora polled, so the correlations are based on the overlapping words. Kučera-Francis is the rated frequency in the Kučera-Francis corpus (Kučera \& Francis, 1967), in which the ratings range from 1 to 69 occurrences, with a mean of 2.9 and a standard deviation of 4.5 . London-Lund frequency is the frequency of occurrence in verbal language derived from the London-Lund corpus of English conversation by Brown (1984), in which the range of entries is $0-6,833$, with a mean of 35 and a standard deviation of 252. Coltheart familiarity is a familiarity rating derived by merging (described by Coltheart, 1981) three sets of familiarity norms: Paivio (1981), Toglia and Battig (1978), and Gilhooly and Logie (1980). The values range from 100 to 700 , with a mean of 488 and a standard deviation of 99 . All of the correlations reported in Table 3 are statistically significant $(p<.05)$.

The correlation between the familiarity ratings performed by our subjects and Coltheart familiarity (Coltheart, 1981) was extremely high $(r=.92, p<.01)$. This suggests that our subjects had a great deal in common with the subjects who participated in those studies. Although this does not necessarily mean that the familiar-

Table 2

Percentage of Responses at Each Pronounceability Rating for Names and Nouns

\begin{tabular}{lccccccc}
\hline & $\begin{array}{c}\text { Very } \\
\text { difficult }\end{array}$ & & & & & & \\
& 1 & 2 & 3 & 4 & 5 & 6 & $\begin{array}{c}\text { Very } \\
\text { easy }\end{array}$ \\
\hline Names & 5.0 & 6.1 & 8.9 & 11.7 & 13.9 & 14.3 & 40.1 \\
Nouns & 0.1 & 0.3 & 1.4 & 3.5 & 7.3 & 11.3 & 76.1 \\
\hline
\end{tabular}


Table 3

Correlations Among Variables for the Noun Data

\begin{tabular}{lccccc}
\hline Corpus & K-F & PU & PU & L-L & $\begin{array}{c}\text { C } \\
\text { Freq }\end{array}$ \\
\hline K-F & - & $.26^{*}$ & $.23^{*}$ & .09 & .23 \\
PU Fam & & - & $.63^{*}$ & $.35^{*}$ & $.92^{*}$ \\
PU Pron & & & - & $.23^{*}$ & $.71^{*}$ \\
L-L Freq & & & & - & $.45^{*}$ \\
C Fam & & & & & -
\end{tabular}

Note-The abbreviations and their meanings are as follows: $\mathrm{K}-\mathrm{F}$, Kučera \& Francis (1967); PU Fam, Purdue University familiarity; PU Pron, Purdue University pronounceability; L-L Freq, London-Lund frequency (Brown, 1984); C Fam, Coltheart familiarity (Coltheart, 1981). The numbers of observations for each corpus are as follows: for K-F, PU Fam, and PU Pron, 199; for L-L Freq, 109; and for C Fam, 70. ${ }^{*} p<.05$.

ity of names from our sample will be generalizable to other populations, it is suggestive that the ratings might be of broad applicability. The correlations between our measure of familiarity and frequency measured by Kučera and Francis (1967) and the London-Lund corpus (Brown, 1984) were more modest, but they were of comparable size to correlations found in other investigations (e.g., Paivio et al., 1968). These data are consistent with past research (e.g., Gilhooly \& Logie, 1980), in showing a small but reliable correlation between familiarity and frequency in common nouns: Although familiarity and frequency are related, people can be very familiar with words that appear infrequently in the corpus.

There was a reliable correlation of .63 between ratings of the pronounceability of nouns and our ratings of familiarity (Purdue University familiarity), as well as a substantial correlation (.71) with Coltheart familiarity derived by merging three sets of familiarity norms described above (Coltheart, 1981). One other substantial correlation was a large negative correlation with the number of syllables $(-.67 ; p<.01)$. This suggests that the greater the number of syllables in the word, the harder subjects judge the word to pronounce. Interestingly, the correlation between frequency (as measured by the Kučera-Francis corpus) and pronounceability of nouns was a very small (.23), although this was statistically significant $(p<.05)$.

Correlations for our familiarity and pronounceability ratings and frequency of occurrence in the Purdue phone book, as well as number of syllables, are shown in Table 4 . Purdue University frequency refers to the frequency of the names in the Purdue University phone book. The range of entries is $1-693$ occurrences, with a mean of 2.7 and a standard deviation of 9.4. Syllables refers to the number of syllables in the word or name. There was a moderate and reliable correlation between phone-book frequency and mean ratings of familiarity $(.42 ; p<.05)$ and a small, but reliable, negative correlation between the number of syllables and the mean familiarity ranking $(-.27 ; p<.05)$. Like words, frequency and familiarity are only slightly related in names.

As with the nouns, pronounceability was only slightly correlated with actual phone-book frequency $(.21 ; p=$ $.05)$ in the name ratings. However, the correlation with number of syllables was much smaller than the comparable correlation between syllables and ratings of word pronounceability $(-.43, p<.05)$, although still reliable. Finally, the correlation between pronounceability ratings and our familiarity was very high $(.74, p<.05)$. The factor that most strongly predicted pronounceability is the familiarity of the name.

Table 5 shows the statistics for nouns and names broken down by the number of syllables. Surprisingly, given that we picked the nouns and names randomly from different corpora, the distribution of syllables was somewhat similar, except that the name stimuli consisted of more two-syllable items than one-syllable items, whereas the noun stimuli were equally distributed across one- and two-syllable items. However, even when looking at a comparable syllable number, the names were rated as substantially less familiar and less pronounceable. In fact, one-syllable names were rated as less familiar and harder to pronounce than five-syllable words.

Given our ultimate goal of predicting how difficult it is to pronounce a particular name, we performed a multiple regression with pronounceability as the dependent variable and phone book frequency, familiarity, and syllables as predictors. The multiple-regression coefficient was $79(p<.05)$, which is not a very large increase in predictive power from just using familiarity alone given that the simple correlation between familiarity and pronounceability was .74. A partial correlation between familiarity rating and pronounceability rating, with phonebook frequency and syllables partialed out, was .72, which supports the suggestion that familiarity alone does a very good job of predicting pronounceability and that phonebook frequency and number of syllables do not add anything substantial above and beyond familiarity.

Our data compare quite closely to those collected by Zeichmeister et al. (1975). They found a strong relationship in the surname data between familiarity and pronounceability of .77 , which is very close to our .74. In addition, they reported much smaller correlations between pronounceability and frequency (.36 vs. our .21), as well as familiarity and frequency (.57 vs. our .42). However, we added a direct comparison between names and nouns and showed that the distributions of familiarity and pronounceability ratings are quite different across the different word types. In addition, the analysis above suggests that familiarity alone is a strong predictor of pronounceability.

Table 4

Correlations Among Variables for the Name Data

\begin{tabular}{lcccc} 
& PU & & PU & PU \\
Corpus & Freq & Syllables & Fam & Pron \\
\hline PU Freq & - & -.06 & $.42^{*}$ & $.21^{*}$ \\
Syllables & & - & $-.27^{*}$ & $-.43^{*}$ \\
PU Fam & & & - & $.74^{*}$ \\
PU Pron & & & & -
\end{tabular}

Note--The abbreviations and their meanings are as follows: PU Freq, Purdue University frequency (Purdue University phone book); PU Fam, Purdue University familiarity; PU Pron, Purdue University pronounceability. The number of observations for each corpus (PU Freq, Syllables, PU Fam, and PU Pron) is $199 .{ }^{*} p<.05$. 
Table 5

Average Frequency, Familiarity, and Pronounceability of Nouns and Names as a Function of Number of Syllables

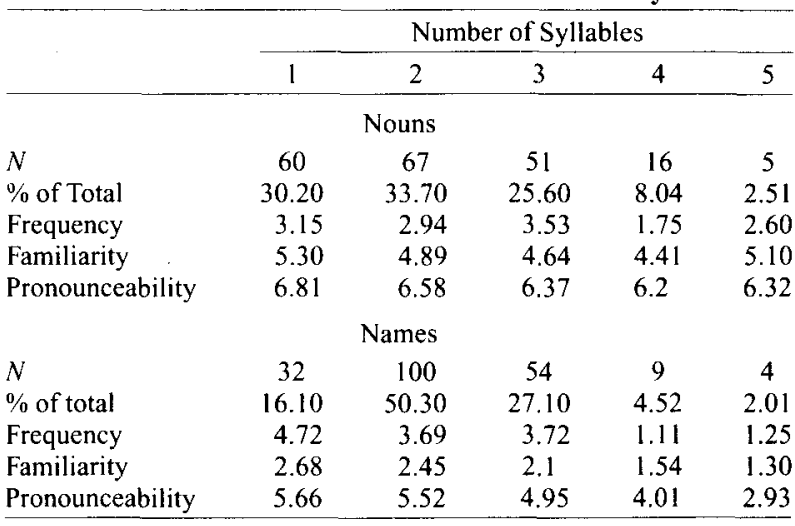

One might question whether rated pronounceability has anything to do with actual difficulty in pronunciation. There remains the possibility that confidence in the ability to pronounce a name is completely unrelated to how difficult a name is to pronounce in practice. Thus, in Experiment 2 , we asked subjects to actually pronounce a subset of the names and also to rate the names on pronounceability both before and after the pronunciation task. In addition, we measured how long it took the subjects to pronounce the name, when they were under no time pressure. There should be a strong relationship between rated pronounceability and how long it takes to figure out how to pronounce it.

\section{EXPERIMENT 2}

In Experiment 2, we were interested in using the ratings collected above to predict actual ease of pronunciation of names. We asked subjects to perform the familiarity and pronounceability ratings twice: once before they attempted to pronounce the names and once after. We also measured naming latency to collect another measure of difficulty of pronunciation. If the rated pronounceability is directly related to ease or difficulty of pronouncing a name, we expected to see an increase in time to begin the utterance with an increase in rated difficulty of pronunciation. In addition, although we expected that ratings of familiarity in particular would go up across rating episodes, the relationship among the names in both familiarity and pronounceability ratings was expected to stay fairly constant if actually producing a name did not change the subject's impression of how difficult the names were to pronounce.

\section{Method}

\section{Stimuli and Apparatus}

The dialect questionnaire, familiarity, and pronounceability rating forms described above were also used in Experiment 2. Fifty names were randomly selected for the pronunciation task.

For the production task, each subject was seated comfortably in a double-walled sound-treated chamber with antireverberation cushion layers. A head-worn microphone (Pro series) was used to maintain a constant distance between the mouth of the speaker and the microphone. Speech samples were recorded onto a digital audio tape at a $44.1-\mathrm{kHz}$ sampling rate.

\section{Subjects}

Eighteen Purdue University graduate and undergraduate students ranging in ages from 18 to 30 years volunteered to participate in this experiment in exchange for $\$ 5 /$ hour. The experiment was conducted in three $1-h$ sessions.

\section{Procedure}

As in Experiment 1, all subjects first filled out the dialect questionnaire and rated the familiarity and pronounceability of the 199 names using the rating scales and instructions described for Experiment 1 .

The subjects were told that we were interested in learning about how people pronounce names. They were shown a name on the screen and were asked to think about how to pronounce it and then to speak the name clearly. They were asked to pronounce the names like they would if they were calling information to get that person's phone number. The names appeared one at a time on the screen, and the subjects were given as long as needed to pronounce each name. A computer tone accompanied the appearance of each name on the screen. The subjects had 10 practice trials and then were given a randomized list of 250 names. Names were presented across two different data collection sessions. Each session contained five repetitions of each of the 50 names in random order.

Finally, the subjects were asked to rerate the 199 names for familiarity and pronounceability. The subjects were then debriefed and thanked.

\section{Results and Discussion}

The familiarity and pronounceability ratings collected in this experiment correlated quite highly with the ratings collected in Experiment 1. Familiarity ratings had correlations of .90 and .85 for the two rating episodes, respectively, and pronounceability correlated .95 and .91 (all $p s<.05$ ). When the data were restricted to just the 50 names that were pronounced, the correlations were similar at .90 and .80 for the two familiarity ratings and .93 and .90 for the two pronounceability ratings (all $p s<.05$ ).

We also collected the latency from the onset of the cue to begin pronouncing (computer tone) to the beginning of the utterance. The subjects were instructed to think about each name before pronouncing it and were not told that their latency was being measured. Thus, the latencies were very slow. Average time to begin the utterance across the names was $11.8 \mathrm{sec}$, with a standard deviation of $7.8 \mathrm{sec}$. Even though these latencies were extremely long, they are still a useful indicator of the difficulty that the subjects had with the names. This is shown in the correlation between pronunciation latency and rated pronounceability, which were highly negatively correlated $(-.74 ; p<.05)$. The more difficult the rated pronounceability, the longer it took for the subjects to begin pronouncing the name. Familiarity was also significantly correlated with latency $(-.51, p<.05)$

Analyzing the actual utterances produced by the subjects is not a straightforward problem. There are many ways in which the variability of the actual pronuciations can be measured and quantified. We chose a method called dynamic time warping (DTW) (Itakura, 1975; Sakoe \& 
Chiba, 1978), a template-matching procedure that shrinks or extends certain features of the test item to achieve the best match with a template. DTW uses a dynamic programming technique to nonlinearly adjust, or warp, the parametric representation of a speech test utterance to the parametric representation of a reference template. The goal of DTW is to synchronize similar acoustic segments from the test utterance and the template so that the distance measured between the two utterances is based on an optimal time alignment. The parameters are the measured speech features, typically cepstral coefficients representing the speech spectrum. In Experiment 2, DTW was used to create a master template for each name. This template represents the centroid of the training tokens for that utterance with respect to the parameter space. In recognition, the test utterance was compared with each of the templates, using DTW for the time alignment and distance computation. We took the standard deviation of the distance computation for each name as an index of the variability of the utterances.

The correlation between this measure and rated pronounceability was $-.48(p<.05)$, showing that, as the rated ease of pronounceability increased, the variability of the pronunciations decreased. The correlation between familiarity and our variability measure was also significant $(-.35, p<.05)$. Although the correlation with the pronounceability measure was not as high as we would like, the distance measure was somewhat crude, and there are a number of other possibilities for computing variability in pronunciation. We are considering clustering methods that will be a better method for computing the variability of the pronunciations.

In Experiment 2, we used latency as one measure of the difficulty of pronunciation of the names. Even though the subjects were not told that their latencies were being measured, we found that rated pronounceability and latency were highly correlated, indicating that the subject's subjective feeling about how easy or difficult it is to pronounce a word is actually related to performance. In addition, we found that the relationships among the names in terms of how difficult they were to pronounce was not affected by the pronunciation task. We also found that a measure of the variability of the actual pronunciations of the names correlated reliably with rated pronounceability.

\section{GENERAL DISCUSSION}

The raw data from each experiment can be accessed at http://www.psych.purdue.edu/ aimee/names.html. Means and standard deviations for each name for phone-book frequency, familiarity, and pronounceability are also reproduced in the Appendices.

The data reported here confirm our intuitions that there are substantial differences in how names and nouns are rated. The randomly selected nouns used in these experiments were rated as more familiar and easier to pronounce than the randomly selected surnames. In other ways, the ratings of noun and name sets were quite similar. For both sets, there were modest correlations between writ- ten frequency counts and familiarity ratings. Recall that the frequency count used for names was simply the number of occurrences of the name in the Purdue phone book. This is a crude way of assessing frequency that does not take into account how often a person might encounter a name in actual usage. That is, a name that is uncommon (has a low frequency in the Purdue directory) may be encountered quite frequently (e.g., if the name belongs to a well-known person). Strong correlations were found for both names and nouns between familiarity ratings and pronounceability ratings; the subjects rated familiar items as easier to pronounce than unfamiliar items, and vice versa. For both names and nouns, familiarity was a better predictor of pronounceability than was written frequency, but frequency counts were much easier to obtain.

Our data on the words are very comparable to other ratings found in the literature. Our familiarity ratings correlated very well with other ratings of familiarity (Coltheart, 1981). In addition, we replicated the modest correlation between frequency and familiarity found numerous times in the literature (Coltheart, 1981).

Our name data are slightly different from those of Whalen and Zsiga (1994), who found that the relationship between frequency and familiarity was higher for nouns than for names. However, their stimuli were noun/ first-name homophones, whereas surnames were used in this study. When surnames were rated for familiarity, they showed about the same relationship with frequency as nouns. These data replicate and extend the findings of Zechmeister et al. (1975), who showed a strong relationship between rated familiarity and pronounceability for surnames. Our data also show that the distributional characteristics of nouns and names are very different. We also showed a substantial relationship between rated pronounceability and the time taken to actually start producing a name. This is taken as confirming evidence supporting our contention that pronounceability ratings are related to actual difficulty in pronunciation in practice.

These results have a number of implications for the study of human recognition of spoken names and for computer speech recognition systems. The data reported here do not support or deny the notion that proper names occupy a unique position in the mental lexicon. It is possible that names are on one end of the continuum between very familiar words and nonwords. Although these data were collected using a fairly restricted group of subjects (Purdue University undergraduates), there are a number of ways that these data could be useful to other investigators. First, the comparison of the distributions of nouns and names is something that has not been demonstrated in the literature. A researcher interested in lexical access might conclude that some names act like nonwords because of the distribution of names on the far side of familiarity. Second, empirical tests of memory and lexical access for names could use our ratings to explore whether familiarity has the same effects as it does on other nouns. This could influence theories of lexical access of names by showing similarities or differences between the types of stimuli. 
One possible difficulty in directly comparing the noun and name ratings is that the data were collected in distinct blocks, and the raters might have used the rating scales differently in the two blocks. However, there were no statistical effects for order or form and, thus, no evidence for a switch in rating scale. In addition, although caution must be taken to realize that our ratings have been collected using a particular population, the same care must be taken when using any other type of ratings.

Finally, knowing that ratings of pronounceability of names are very highly related to the familiarity but not as strongly related to number of syllables is an important finding. The data on pronounceability are especially important from the automatic speech recognition viewpoint. On the whole, names are rated as quite unfamiliar and difficult to pronounce, and the familiarity ratings correlate well with ratings of pronounceability. It is highly likely that names that are very familiar will be pronounced with a certain amount of consistency across utterances. On the other hand, it is likely that low-familiarity names will be articulated with a variety of different pronunciations. These features could then be used to build a model for recognizing names that expects names with certain features to be pronounced consistently and others to have a wider range of pronunciations. This would allow the construction of a model that expects that some names will be pronounced more consistently than others.

These data are an important first step in improving performance of computer speech recognition systems on proper names. The results of this study provide basic distributional information about proper names, and, more significantly, they describe some ways in which names differ from common nouns. These results will be used to justify, in part, using different processing strategies for names and for incorporating information on familiarity or pronounceability into automatic speech recognition systems.

\section{REFERENCES}

Brown, G. D. A. (1984). A frequency count of 190,000 words in the London-Lund Corpus of English Conversation. Behavior Research Methods, Instruments, \& Computers, 16, 502-532.

Burke, D. M., Mackay, D. G., Worthley, J. S., \& Wade, E. (1991). On the tip-of-the-tongue: What causes word finding failures in young and older adults? Journal of Memory \& Language, 30, 542-579.

Burton, A. M., \& BRUCE, V. (1992). I recognize your face but I can't remember your name: A simple explanation? British Journal of Psychologv, 83, 45-60.

CoHen, G. (1990). Why is it difficult to put names to faces? British Journal of Psychology, 81, 287-297.

Cohen, G., \& Burke, D. M. (1993). Memory for proper names: A review. Memorv, 1, 249-263.

Cohen, G., \& Faulkner, D. (1986). Memory for proper names: Age differences in retrieval. British Journal of Developmental Psychology, 4, 187-197.

ColTheArT, M. (1981). The MRC psycholinguistic database. Quarterly Journal of Experimental Psychology, 33A, 497-505.

Coltheart, M., Curtis, B., Atkins, P., \& Haller, M. (1993). Models of reading aloud: Dual-route and parallel-distributed-processing approaches. Psychological Review, 100, 589-608.

Deshmukh, N., Ngan, J., Hamaker, J., \& Picone, J. (1997, April), An advanced system to generate pronunciations of proper nouns. In Proceedings of the 1997 IEEE International Conference on Acoustics,
Speech, and Signal Processing (pp. 1467-1470). Piscataway, NJ: IEEE.

FORSTER, K. I. (1979). Levels of processing and the structure of the language processor. In W. E. Cooper \& E. C. T. Walker (Eds.), Sentence processing: Psycholinguistic studies presented to Merrill Garrett (pp. 27-85). Hillsdale, NJ: Erlbaum.

GiLhooly, K. J., \& LoGIE, R. H. (1980). Meaning-dependent ratings of imagery, age-of-acquisition, familiarity, and concreteness for 387 ambiguous words. Behavior Research Methods \& Instrumentation, 12, 428-450.

Howes, D. H. (1957). On the relation between the intelligibility and frequency of occurrence of English words. Journal of the Acoustical Society of America, 29, 296-305.

ITAKURA, F. (1975). Minimum prediction residual principle applied to speech recognition. IEEE Transactions on Acoustics, Speech, \& Signal Processing, ASSP-23, 67-72.

Kamm, C. A., Shamieh, C. R., \& Singhal, S. (1995). Speech recognition issues for directory assistance applications. Speech Communication, 17, 303-311.

KuČERA, H., \& Francis, W. (1967). Computational analysis of presentday American English. Providence, RI: Brown University Press.

LenNig, M., Bielby, G., \& Massicotte, J. (1995). Directory assistance automation in Bell Canada: Trial results. Speech Communication, 17, 227-234.

LEVELT, W. J. M. (1992). Accessing words in speech production: Stages, processes and representations. Cognition, 42, 1-22.

Lucchelli, F., \& De Renzi, E. (1992). Proper name anomia. Cortex, 28, 221-230.

Marcus, M., Santorinin, B., \& Marcinkiewicz, M. A. (1993). Building a large annotated corpus of English: The Penn Treebank. Computational Linguistics, 19, 313-330.

MONSELL, S. (1991). The nature and locus of word frequency effects in reading. In D. Besner \& G. W. Humphreys (Eds.), Basic processes in reading: Visual word recognition (pp. 148-197). Hillsdale, NJ: Erlbaum.

Morton, J. (1969). The interaction of information in word recognition. Psychological Review, 76, 165-178.

Newbigging, P. L. (1961). The perceptual reintegration of frequent and infrequent words. Canadian Journal of Psychology, 15, 123-132.

Paivio, A. V. (1981). [Expansion of the norms of Paivio, Yuille, and Madigan, 1968]. Unpublished raw data.

Paivio, A. V., Yuille, J. C., \& Madigan, S. A. (1968). Concreteness, imagery and meaningfulness values for 925 nouns. Journal of Experimental Psychology Monograph, 76(3, Pt. 2).

Quine, W. V. O. (1960). Word and object. Cambridge, MA: MIT Press. SAKOE, H., \& CHIBA, S. (1978). Dynamic programming algorithm optimization for spoken word recognition. IEEE Transactions on Acoustics, Speech, \& Signal Processing, ASSP-26, 43-49

Savin, H. B. (1963). Word-frequency effect and errors in the perception of speech. Journal of the Acoustical Society of America, 35, 200-206.

Soloman, R. L., \& Postman, L. (1952). Frequency of usage as a determinant of recognition thresholds for words. Journal of Experimental Psychology, 43, 195-201.

THEDE, S. M. (1998). Predicting part-of-speech information about unknown words using statistical methods. In Proceedings of Coling-ACL 1998 (pp. 1505-1507). Montreal: Association for Computational Linguistics.

Toglia, M. P., \& Battig, W. F. (1978). Handbook of semantic word norms. Hillsdale, NJ: Erlbaum.

VALENTINE, T., BRENnEN, T., \& BRÉDART, S. (1996). The cognitive psychology of proper names. London: Routledge.

Vysotsky, G. J. (1995). VoiceDialing(TM)-The first speech recognition based service delivered to customer's home from the telephone network. Speech Communication, 17, 235-247.

Whal.EN, D. H., \& Zsiga, E. C. (1994). Subjective familiarity of English word/name homophones. Behavior Research Methods, Instruments, \& Computers, 26, 402-408.

Young, A. W., Ellis, A. W., \& Flude, B. M. (1988). Accessing stored information about people. Psychological Research, 50, 111-115.

Zechmeister, E. G., King, J., Gude, C., \& Opera-Nadi, B. (1975). Ratings of frequency, familiarity, orthographic distinctiveness and pronunciability for 192 surnames. Behavior Research Methods \& Instrumentation, 7, 531-533. 
APPENDIX A

Actual Frequency Count, Ratings of Familiarity (Means and Standard Deviations), and Ratings of Pronounceability (Means and Standard Deviations) of Words

\begin{tabular}{|c|c|c|c|c|c|c|c|c|c|c|c|}
\hline \multirow[b]{2}{*}{ Word } & \multirow{2}{*}{$\begin{array}{c}\mathrm{K}-\mathrm{F} \\
\text { Frequency }\end{array}$} & \multicolumn{2}{|c|}{ Familiarity } & \multicolumn{2}{|c|}{ Pronounceability } & \multirow[b]{2}{*}{ Word } & \multirow{2}{*}{$\begin{array}{c}\mathrm{K}-\mathrm{F} \\
\text { Frequency }\end{array}$} & \multicolumn{2}{|c|}{ Familiarity } & \multicolumn{2}{|c|}{ Pronounceability } \\
\hline & & $M$ & $S D$ & $M$ & $S D$ & & & $M$ & $S D$ & $M$ & $S D$ \\
\hline acceptance & 3 & 5.00 & 1.59 & 6.43 & 1.11 & fans & 1 & 5.69 & 1.29 & 6.84 & 0.57 \\
\hline accordion & 1 & 3.17 & 1.76 & 6.05 & 1.26 & filibusters & 1 & 2.53 & 1.49 & 5.73 & 1.56 \\
\hline achievement & 6 & 5.29 & 1.48 & 6.41 & 1.11 & flow & 4 & 4.95 & 1.62 & 6.91 & 0.29 \\
\hline acquaintance & 1 & 4.41 & 1.63 & 5.98 & 1.42 & fly & 3 & 5.95 & 1.26 & 6.93 & 0.25 \\
\hline acreage & 2 & 3.57 & 2.17 & 5.55 & 1.37 & founding & 1 & 4.07 & 1.69 & 6.55 & 0.93 \\
\hline advances & 1 & 4.90 & 1.51 & 6.50 & 1.02 & fronts & 3 & 4.40 & 1.72 & 6.64 & 0.78 \\
\hline advertising & 3 & 5.38 & 1.57 & 6.20 & 1.32 & gains & 6 & 4.64 & 1.53 & 6.75 & 0.61 \\
\hline appeasement & 1 & 3.05 & 1.58 & 5.86 & 1.39 & gallery & 10 & 4.62 & 1.79 & 6.66 & 0.68 \\
\hline arrival & 1 & 4.67 & 1.60 & 6.64 & 0.72 & general & 4 & 5.48 & 1.35 & 6.61 & 0.87 \\
\hline assignments & 1 & 6.38 & 1.09 & 6.57 & 0.90 & gin & 12 & 4.86 & 1.87 & 6.75 & 0.72 \\
\hline banquet & 1 & 4.62 & 1.61 & 6.48 & 0.88 & goods & 3 & 5.29 & 1.46 & 6.77 & 0.57 \\
\hline belting & 1 & 3.48 & 1.72 & 6.52 & 0.88 & grabbing & 1 & 4.50 & 1.60 & 6.70 & 0.73 \\
\hline birdie & 4 & 4.91 & 1.73 & 6.61 & 0.78 & graduate & 1 & 5.76 & 1.38 & 6.57 & 0.82 \\
\hline bottling & 1 & 4.59 & 1.68 & 6.05 & 1.06 & grain & 1 & 4.72 & 1.89 & 6.82 & 0.39 \\
\hline breakfast & 2 & 6.10 & 1.28 & 6.70 & 0.70 & grants & 2 & 4.81 & 1.62 & 6.80 & 0.55 \\
\hline breakups & 1 & 5.05 & 1.54 & 6.70 & 0.59 & grass & 2 & 6.26 & 1.09 & 6.82 & 0.50 \\
\hline brother & 4 & 5.95 & 1.55 & 6.70 & 0.76 & groupings & 2 & 4.24 & 1.69 & 6.52 & 0.79 \\
\hline buyers & 2 & 5.05 & 1.55 & 6.41 & 0.97 & hamlet & 1 & 3.47 & 1.84 & 6.70 & 0.70 \\
\hline campaign & 5 & 4.81 & 1.58 & 6.32 & 1.14 & hat & 1 & 6.45 & 0.80 & 6.89 & 0.49 \\
\hline careers & 2 & 5.79 & 1.18 & 6.64 & 0.75 & headlines & 1 & 4.98 & 1.70 & 6.64 & 0.81 \\
\hline centers & 2 & 4.98 & 1.56 & 6.61 & 0.87 & hitter & 1 & 4.66 & 1.70 & 6.70 & 0.82 \\
\hline cheer & 1 & 5.43 & 1.43 & 6.82 & 0.58 & hog & 1 & 5.33 & 1.62 & 6.89 & 0.62 \\
\hline client & 4 & 4.83 & 1.70 & 6.55 & 0.98 & hopes & 4 & 5.60 & 1.41 & 6.70 & 0.82 \\
\hline climate & 5 & 5.14 & 1.52 & 6.68 & 0.71 & house & 8 & 6.43 & 1.01 & 6.80 & 0.70 \\
\hline clothing & 21 & 5.83 & 1.39 & 6.66 & 0.71 & inadequacy & 1 & 3.86 & 1.75 & 5.91 & 1.34 \\
\hline coach & 4 & 5.34 & 1.69 & 6.89 & 0.39 & injury & 13 & 5.64 & 1.21 & 6.59 & 0.79 \\
\hline colleges & 7 & 6.43 & 0.96 & 6.57 & 0.90 & instincts & 1 & 4.83 & 1.65 & 6.57 & 0.90 \\
\hline committee & 17 & 5.16 & 1.61 & 6.34 & 1.06 & institution & 5 & 4.79 & 1.72 & 6.28 & 1.16 \\
\hline commodities & 2 & 3.60 & 1.87 & 6.09 & 1.38 & insult & 1 & 5.43 & 1.48 & 6.80 & 0.55 \\
\hline comradeship & 2 & 3.05 & 1.78 & 5.34 & 1.58 & interview & 1 & 5.40 & 1.59 & 6.57 & 0.79 \\
\hline conductor & 1 & 4.21 & 1.79 & 6.57 & 0.97 & investors & 10 & 4.40 & 1.62 & 6.57 & 0.85 \\
\hline consultation & 1 & 4.07 & 1.83 & 6.07 & 1.40 & invitation & 1 & 4.98 & 1.62 & 6.41 & 1.02 \\
\hline continents & 1 & 4.57 & 1.71 & 6.27 & 1.26 & journalist & 1 & 4.88 & 1.63 & 6.48 & 1.05 \\
\hline contrast & 1 & 4.84 & 1.45 & 6.52 & 0.93 & knocks & 5 & 4.84 & 1.59 & 6.82 & 0.54 \\
\hline convention & 1 & 4.57 & 1.81 & 6.57 & 0.87 & landscape & 1 & 5.16 & 1.54 & 6.61 & 0.81 \\
\hline cookies & 1 & 5.88 & 1.42 & 6.80 & 0.63 & legend & 1 & 4.95 & 1.67 & 6.64 & 0.84 \\
\hline correspondence & 1 & 4.09 & 1.89 & 6.11 & 1.32 & legislator & 2 & 4.12 & 1.77 & 6.05 & 1.33 \\
\hline county & 16 & 5.76 & 1.45 & 6.55 & 0.93 & liberty & 1 & 4.59 & 1.67 & 6.64 & 0.72 \\
\hline credit & 3 & 5.86 & 1.38 & 6.70 & 0.73 & life & 9 & 6.26 & 1.16 & 6.68 & 1.12 \\
\hline criticisms & 1 & 4.48 & 1.80 & 6.05 & 1.35 & limitations & 1 & 4.69 & 1.67 & 6.34 & 0.99 \\
\hline crowd & 2 & 5.62 & 1.28 & 6.77 & 0.60 & look & 1 & 6.19 & 1.03 & 6.86 & 0.35 \\
\hline crowns & 1 & 4.29 & 1.85 & 6.84 & 0.48 & loss & 1 & 5.31 & 1.44 & 6.98 & 0.15 \\
\hline cruelty & 1 & 4.47 & 1.70 & 6.32 & 1.20 & lovers & 1 & 5.83 & 1.35 & 6.80 & 0.51 \\
\hline dates & 2 & 5.93 & 1.14 & 6.80 & 0.46 & mails & 3 & 4.38 & 1.97 & 6.86 & 0.41 \\
\hline decisions & 5 & 6.10 & 1.24 & 6.52 & 1.00 & manufacturing & 3 & 5.34 & 1.61 & 6.25 & 1.10 \\
\hline denials & 1 & 4.19 & 1.65 & 6.48 & 1.09 & masons & 1 & 3.40 & 1.85 & 6.55 & 1.00 \\
\hline designer & 2 & 4.81 & 1.62 & 6.52 & 0.90 & match & 1 & 5.57 & 1.42 & 6.84 & 0.48 \\
\hline disputes & 2 & 4.33 & 1.68 & 6.53 & 0.85 & measure & 8 & 5.47 & 1.56 & 6.66 & 0.64 \\
\hline duel & 2 & 4.19 & 1.96 & 6.59 & 0.87 & mechanics & 2 & 5.29 & 1.52 & 6.23 & 1.12 \\
\hline echoes & 1 & 4.22 & 1.77 & 6.57 & 0.79 & miles & 5 & 6.17 & 1.19 & 6.68 & 0.77 \\
\hline economics & 2 & 5.04 & 1.66 & 6.43 & 1.09 & minds & 1 & 5.62 & 1.46 & 6.77 & 0.57 \\
\hline element & 1 & 4.71 & 1.60 & 6.52 & 0.85 & muscles & 1 & 5.97 & 1.14 & 6.39 & 1.15 \\
\hline employment & 6 & 5.69 & 1.34 & 6.70 & 0.82 & museum & 3 & 5.24 & 1.49 & 6.25 & 1.26 \\
\hline enigma & 1 & 3.36 & 1.75 & 6.00 & 1.40 & numbers & 3 & 6.50 & 0.73 & 6.75 & 0.61 \\
\hline enrollments & 1 & 4.97 & 1.50 & 6.39 & 1.10 & nuns & 1 & 4.17 & 1.68 & 6.89 & 0.32 \\
\hline epicure & 1 & 2.17 & 1.61 & 5.41 & 1.80 & operators & 1 & 4.81 & 1.58 & 6.61 & 0.75 \\
\hline episodes & 1 & 5.00 & 1.59 & 6.41 & 1.11 & opportunities & 1 & 5.74 & 1.42 & 6.52 & 0.95 \\
\hline equipment & 25 & 5.48 & 1.39 & 6.52 & 0.85 & opportunity & 7 & 5.48 & 1.49 & 6.55 & 0.98 \\
\hline ethics & 1 & 4.83 & 1.75 & 6.61 & 0.75 & ouster & 1 & 1.97 & 1.35 & 5.75 & 1.42 \\
\hline exchanges & 2 & 5.03 & 1.58 & 6.50 & 0.88 & outsiders & 2 & 4.26 & 1.63 & 6.50 & 0.90 \\
\hline extreme & 1 & 5.41 & 1.45 & 6.57 & 0.97 & pair & 4 & 5.53 & 1.31 & 6.91 & 0.29 \\
\hline fancy & 1 & 4.98 & 1.68 & 6.77 & 0.57 & palm & 1 & 5.03 & 1.65 & 6.84 & 0.48 \\
\hline
\end{tabular}


APPENDIX A (Continued)

\begin{tabular}{|c|c|c|c|c|c|c|c|c|c|c|c|}
\hline \multirow[b]{2}{*}{ Word } & \multirow{2}{*}{$\begin{array}{c}\mathrm{K}-\mathrm{F} \\
\text { Frequency }\end{array}$} & \multicolumn{2}{|c|}{ Familiarity } & \multicolumn{2}{|c|}{ Pronounceability } & \multirow[b]{2}{*}{ Word } & \multirow{2}{*}{$\begin{array}{c}\mathrm{K}-\mathrm{F} \\
\text { Frequency }\end{array}$} & \multicolumn{2}{|c|}{ Familiarity } & \multicolumn{2}{|c|}{ Pronounceability } \\
\hline & & $M$ & $S D$ & $M$ & $S D$ & & & $M$ & $S D$ & $M$ & $S D$ \\
\hline past & 7 & 5.57 & 1.33 & 6.91 & 0.42 & sentiment & 1 & 4.21 & 1.52 & 6.14 & 1.25 \\
\hline patronage & 1 & 4.02 & 1.66 & 6.30 & 1.09 & series & 7 & 5.22 & 1.67 & 6.73 & 0.76 \\
\hline percentage & 4 & 5.47 & 1.43 & 6.36 & 1.10 & show & 6 & 5.78 & 1.26 & 6.89 & 0.39 \\
\hline peril & 1 & 3.12 & 1.50 & 6.27 & 1.28 & size & 5 & 5.59 & 1.41 & 6.91 & 0.29 \\
\hline period & 11 & 5.88 & 1.33 & 6.68 & 0.67 & skies & 1 & 5.53 & 1.45 & 6.77 & 0.60 \\
\hline place & 3 & 5.52 & 1.35 & 6.73 & 0.79 & sky & 2 & 6.29 & 0.90 & 6.84 & 0.48 \\
\hline play & 4 & 6.24 & 1.19 & 6.95 & 0.21 & skyjackers & 1 & 2.36 & 1.41 & 6.20 & 1.32 \\
\hline player & 3 & 6.02 & 1.15 & 6.77 & 0.64 & slugger & 3 & 4.34 & 1.65 & 6.77 & 0.57 \\
\hline ponies & 1 & 3.98 & 1.88 & 6.55 & 0.87 & spirit & 12 & 5.14 & 1.79 & 6.73 & 0.59 \\
\hline praise & 2 & 5.12 & 1.60 & 6.73 & 0.69 & squad & 2 & 4.64 & 1.64 & 6.75 & 0.61 \\
\hline principal & 4 & 5.07 & 1.54 & 6.59 & 0.79 & stakes & 1 & 4.36 & 1.72 & 6.80 & 0.51 \\
\hline productivity & 1 & 5.05 & 1.61 & 6.39 & 0.92 & stocks & 8 & 4.79 & 1.78 & 6.84 & 0.43 \\
\hline promise & 1 & 5.86 & 1.22 & 6.70 & 0.70 & streams & 1 & 4.74 & 1.58 & 6.80 & 0.51 \\
\hline proposals & 6 & 4.52 & 1.85 & 6.43 & 1.04 & strokes & 7 & 4.59 & 1.72 & 6.70 & 0.59 \\
\hline pun & 4 & 3.83 & 1.93 & 6.73 & 0.79 & success & 4 & 5.57 & 1.34 & 6.48 & 0.95 \\
\hline pursuit & 1 & 4.43 & 1.69 & 6.52 & 0.85 & sums & 1 & 4.72 & 1.65 & 6.89 & 0.32 \\
\hline racing & 1 & 5.36 & 1.50 & 6.73 & 0.59 & surge & 1 & 3.74 & 1.61 & 6.75 & 0.58 \\
\hline racketeer & 1 & 2.74 & 1.63 & 6.09 & 1.39 & survivors & 1 & 4.60 & 1.89 & 6.41 & 1.17 \\
\hline rail & 1 & 4.91 & 1.68 & 6.91 & 0.42 & teamsters & 1 & 3.86 & 2.01 & 6.50 & 0.93 \\
\hline reconstruction & 1 & 4.57 & 1.61 & 6.34 & 1.22 & term & 5 & 5.41 & 1.44 & 6.82 & 0.54 \\
\hline reference & 8 & 5.10 & 1.49 & 6.43 & 1.07 & textile & 11 & 3.53 & 1.95 & 6.36 & 1.06 \\
\hline regents & 1 & 2.84 & 1.62 & 6.02 & 1.23 & ton & 1 & 5.53 & 1.66 & 6.86 & 0.46 \\
\hline regulation & 3 & 4.71 & 1.72 & 6.36 & 0.99 & toss & 1 & 5.02 & 1.65 & 6.91 & 0.29 \\
\hline renewal & 2 & 4.43 & 1.68 & 6.41 & 1.02 & training & 5 & 5.43 & 1.44 & 6.80 & 0.55 \\
\hline rentals & 1 & 4.97 & 1.81 & 6.75 & 0.61 & tribes & 4 & 4.19 & 1.72 & 6.57 & 1.15 \\
\hline reports & 7 & 5.33 & 1.37 & 6.64 & 0.87 & trip & 3 & 5.59 & 1.44 & 6.93 & 0.25 \\
\hline reprisals & 1 & 3.17 & 1.63 & 5.77 & 1.44 & tv & 1 & 6.61 & 1.16 & 6.91 & 0.29 \\
\hline requirements & 2 & 5.62 & 1.32 & 6.27 & 1.30 & upturn & 2 & 3.02 & 1.62 & 6.61 & 0.84 \\
\hline restriction & 1 & 4.79 & 1.59 & 6.43 & 0.95 & volumes & 1 & 4.91 & 1.47 & 6.48 & 0.95 \\
\hline retarded & 1 & 5.29 & 1.65 & 6.50 & 1.02 & walk & 4 & 6.41 & 0.96 & 6.89 & 0.49 \\
\hline returns & 2 & 4.97 & 1.53 & 6.70 & 0.67 & walls & 1 & 5.79 & 1.24 & 6.80 & 0.59 \\
\hline rioting & 1 & 3.95 & 1.81 & 6.52 & 0.90 & weeks & 6 & 6.24 & 1.25 & 6.86 & 0.46 \\
\hline rundown & 2 & 4.34 & 1.82 & 6.66 & 0.71 & welfare & 5 & 4.60 & 1.83 & 6.70 & 0.70 \\
\hline sacrifice & 2 & 4.83 & 1.72 & 6.52 & 0.82 & wheat & 1 & 4.90 & 1.68 & 6.73 & 0.87 \\
\hline salary & 3 & 5.33 & 1.57 & 6.61 & 0.87 & witnesses & 7 & 5.22 & 1.61 & 6.39 & 1.04 \\
\hline scoreboards & 1 & 4.86 & 1.79 & 6.55 & 0.85 & words & 7 & 6.29 & 1.08 & 6.84 & 0.48 \\
\hline sea & 1 & 4.98 & 1.65 & 6.98 & 0.15 & world & 2 & 5.53 & 1.40 & 6.73 & 0.73 \\
\hline section & 1 & 5.72 & 1.25 & 6.66 & 0.71 & & & & & & \\
\hline
\end{tabular}

Note-K-F Frequency refers to the Kučera and Francis (1967) frequency ratings. 
APPENDIX B

Actual Frequency Count, Ratings of Familiarity (Means and Standard Deviations), and Ratings of Pronounceability (Means and Standard Deviations) of Names

\begin{tabular}{|c|c|c|c|c|c|c|c|c|c|c|c|}
\hline \multirow[b]{2}{*}{ Name } & \multirow[b]{2}{*}{ Frequency } & \multicolumn{2}{|c|}{ Familiarity } & \multicolumn{2}{|c|}{ Pronounceability } & \multirow[b]{2}{*}{ Name } & \multirow[b]{2}{*}{ Frequency } & \multicolumn{2}{|c|}{ Familiarity } & \multicolumn{2}{|c|}{ Pronounceability } \\
\hline & & $M$ & $S D$ & $M$ & $S D$ & & & $M$ & $S D$ & $M$ & $S D$ \\
\hline Ahjuder & 111 & 1.05 & 0.22 & 2.80 & 1.73 & Gettes & 1 & 2.43 & 1.57 & 5.57 & 1.45 \\
\hline Aleksandrovic & 1 & 1.38 & 0.88 & 3.23 & 2.02 & Ghosechowdhury & 1 & 1.09 & 0.34 & 1.80 & 1.23 \\
\hline Allen & 107 & 5.93 & 1.34 & 6.93 & 0.45 & Goellner & 1 & 1.78 & 1.30 & 4.64 & 1.79 \\
\hline Aloisio & 2 & 1.45 & 1.24 & 2.91 & 1.70 & Goldstein & 1 & 3.81 & 1.78 & 6.43 & 0.90 \\
\hline Andricks & 1 & 2.16 & 1.54 & 6.09 & 1.05 & Grice & 2 & 1.86 & 1.25 & 5.39 & 1.60 \\
\hline Asam & 1 & 1.55 & 0.98 & 5.05 & 1.84 & Gulden & 1 & 2.07 & 1.37 & 5.77 & 1.31 \\
\hline Asmus & 1 & 1.64 & 1.12 & 5.09 & 1.70 & Gyambiby & 1 & 1.24 & 0.57 & 2.75 & 1.95 \\
\hline Atkinson & 17 & 3.66 & 1.88 & 6.32 & 1.22 & Haberkorn & 1 & 1.41 & 0.86 & 5.23 & 1.84 \\
\hline Avalos & 1 & 2.19 & 1.74 & 5.18 & 1.48 & Hammonds & 2 & 4.55 & 1.78 & 6.77 & 0.57 \\
\hline Bara & 1 & 2.03 & 1.49 & 6.05 & 1.26 & Heichelbech & 3 & 1.79 & 1.29 & 4.20 & 1.68 \\
\hline Bataille & 1 & 1.59 & 0.99 & 4.27 & 1.65 & Hesse & 1 & 2.98 & 1.82 & 5.57 & 1.53 \\
\hline Bause & 1 & 1.97 & 1.38 & 4.91 & 1.74 & Hodina & 1 & 1.38 & 0.67 & 4.95 & 1.63 \\
\hline Bayarri & 1 & 1.28 & 0.81 & 3.73 & 1.63 & Hofer & 4 & 2.50 & 1.70 & 5.77 & 1.31 \\
\hline Beer & 10 & 5.86 & 1.75 & 6.91 & 0.60 & Hoggard & 1 & 2.22 & 1.49 & 6.09 & 1.22 \\
\hline Benitez & 4 & 1.98 & 1.33 & 4.77 & 1.94 & Hoppes & 2 & 2.38 & 1.51 & 5.98 & 1.21 \\
\hline Bissig & 1 & 1.28 & 0.59 & 4.35 & 2.10 & Horvath & 6 & 2.24 & 1.96 & 4.84 & 1.66 \\
\hline Boerstler & 1 & 1.34 & 0.74 & 3.89 & 1.70 & Houseman & 2 & 3.00 & 1.82 & 6.75 & 0.58 \\
\hline Bollinger & 6 & 3.40 & 1.83 & 6.16 & 1.20 & Hsieh & 12 & 1.03 & 0.18 & 2.05 & 1.29 \\
\hline Boscia & 1 & 1.66 & 1.13 & 4.57 & 1.72 & Hunsley & 1 & 2.59 & 1.60 & 6.20 & 0.98 \\
\hline Botich & 1 & 1.67 & 1.08 & 4.43 & 1.78 & Ichniowski & 1 & 1.28 & 0.89 & 3.45 & 1.91 \\
\hline Bousum & 2 & 1.97 & 1.86 & 3.95 & 1.63 & Ippolito & 1 & 1.26 & 0.93 & 3.70 & 1.96 \\
\hline Brehony & 1 & 1.47 & 0.80 & 4.80 & 1.58 & Jasiewicz & 1 & 1.64 & 1.33 & 3.09 & 2.01 \\
\hline Breland & 1 & 1.81 & 1.15 & 5.45 & 1.69 & Jasinski & 3 & 2.28 & 1.55 & 5.16 & 1.68 \\
\hline Brush & 5 & 3.88 & 2.32 & 6.82 & 0.76 & Jaskula & 1 & 1.36 & 0.77 & 4.12 & 1.87 \\
\hline Buehler & 3 & 3.74 & 1.93 & 5.73 & 1.53 & Jauregui & 1 & 1.26 & 0.87 & 2.75 & 1.74 \\
\hline Bulza & 2 & 1.47 & 0.86 & 5.20 & 1.47 & Jerpe & 1 & 1.47 & 1.05 & 4.18 & 1.94 \\
\hline Burney & 4 & 2.88 & 1.70 & 6.32 & 0.96 & Jez & 1 & 1.50 & 0.92 & 5.30 & 1.98 \\
\hline Butcher & 14 & 4.64 & 1.77 & 6.82 & 0.66 & Joern & 1 & 1.43 & 0.92 & 3.93 & 1.80 \\
\hline Cahn & 2 & 2.55 & 1.44 & 6.39 & 0.99 & Kaiser & 25 & 4.26 & 1.84 & 6.45 & 1.13 \\
\hline Candler & 2 & 2.43 & 1.52 & 6.09 & 1.20 & Kamal & 1 & 1.95 & 1.28 & 5.02 & 1.84 \\
\hline Canvin & 1 & 1.76 & 1.13 & 5.55 & 1.52 & Kazlauskas & 1 & 1.36 & 0.83 & 3.09 & 1.87 \\
\hline Caparell & 1 & 1.74 & 0.95 & 5.32 & 1.57 & Keady & 1 & 5.50 & 1.68 & 6.45 & 1.09 \\
\hline Chavarria & 1 & 1.43 & 0.90 & 4.61 & 1.86 & Kenzie & 1 & 3.00 & 1.70 & 5.68 & 1.61 \\
\hline Chittur & 1 & 1.33 & 0.82 & 4.47 & 1.79 & Kompis & 1 & 1.34 & 0.69 & 4.93 & 1.66 \\
\hline Cischke & 1 & 1.26 & 0.78 & 2.93 & 1.40 & Koztecki & 1 & 1.64 & 1.13 & 3.75 & 1.79 \\
\hline Claxton & 5 & 2.02 & 1.22 & 5.95 & 1.51 & Kracium & 1 & 1.24 & 0.60 & 3.77 & 1.88 \\
\hline Coady & 1 & 2.22 & 1.67 & 5.84 & 1.36 & Lapczynski & 1 & 1.29 & 0.84 & 3.18 & 1.97 \\
\hline Coppock & 1 & 1.69 & 1.11 & 5.75 & 1.28 & Last & 1 & 4.40 & 2.22 & 6.91 & 0.36 \\
\hline Cowsert & 1 & 1.64 & 1.21 & 4.61 & 1.83 & Laughton & 1 & 2.72 & 1.55 & 5.73 & 1.47 \\
\hline Cretsinger & 1 & 1.84 & 1.36 & 5.34 & 1.49 & Lingaraj & 2 & 1.24 & 0.88 & 2.84 & 1.70 \\
\hline Daries & 1 & 2.21 & 1.53 & 5.73 & 1.45 & Linvill & 1 & 1.84 & 1.56 & 5.50 & 1.56 \\
\hline Depew & 6 & 2.53 & 1.79 & 5.95 & 1.24 & Lobdell & 2 & 1.64 & 1.07 & 5.07 & 1.90 \\
\hline Dickes & 1 & 2.97 & 1.97 & 5.91 & 1.39 & Logan & 23 & 4.86 & 1.79 & 6.89 & 0.44 \\
\hline Doppelfeld & 2 & 1.64 & 1.02 & 5.73 & 1.42 & Lopez & 34 & 5.09 & 1.79 & 6.66 & 0.78 \\
\hline Dukleski & 1 & 1.57 & 1.06 & 4.57 & 1.85 & Lovins & 1 & 2.45 & 1.65 & 6.23 & 1.27 \\
\hline Earl & 7 & 4.76 & 1.73 & 6.75 & 0.69 & Lupien & 1 & 1.50 & 0.92 & 4.98 & 1.50 \\
\hline Easley & 1 & 2.67 & 1.66 & 6.14 & 1.30 & Lyford & 1 & 1.76 & 1.05 & 5.14 & 1.89 \\
\hline Ecer & 1 & 1.36 & 0.67 & 4.25 & 1.73 & Lyman & 2 & 2.48 & 1.66 & 6.48 & 1.09 \\
\hline Enge & 1 & 1.67 & 1.00 & 4.50 & 1.56 & Mabel & 1 & 3.47 & 1.80 & 6.20 & 1.47 \\
\hline Enriquez & 1 & 2.64 & 1.80 & 4.89 & 2.13 & Mackall & 1 & 2.26 & 1.48 & 5.43 & 1.63 \\
\hline Etheridge & 1 & 4.05 & 1.94 & 6.27 & 1.39 & Maddux & 2 & 4.28 & 2.21 & 6.34 & 1.38 \\
\hline Fayle & 1 & 1.72 & 1.24 & 5.25 & 1.69 & Marble & 2 & 3.64 & 2.02 & 6.77 & 0.80 \\
\hline Fennimore & 1 & 2.29 & 1.50 & 5.70 & 1.50 & Mariga & 2 & 1.71 & 1.30 & 4.59 & 1.69 \\
\hline Filipowski & 2 & 2.17 & 1.81 & 4.77 & 1.82 & Marquez & 5 & 2.90 & 2.05 & 5.48 & 1.89 \\
\hline Fiss & 1 & 1.81 & 1.25 & 6.34 & 1.29 & Mcclymont & 1 & 1.29 & 0.82 & 5.73 & 1.44 \\
\hline Fladhammer & 1 & 1.36 & 0.69 & 5.57 & 1.40 & Meagher & 2 & 2.03 & 1.47 & 4.70 & 1.97 \\
\hline Forston & 1 & 2.26 & 1.65 & 6.05 & 1.24 & Mehta & 4 & 1.19 & 0.40 & 4.05 & 1.93 \\
\hline Franta & 1 & 1.45 & 0.86 & 5.41 & 1.51 & Mohtar & 1 & 1.36 & 0.72 & 4.75 & 1.71 \\
\hline Frantal & 1 & 1.43 & 0.77 & 5.50 & 1.41 & Molina & 3 & 2.16 & 1.56 & 5.95 & 1.31 \\
\hline Friedline & 1 & 1.71 & 1.01 & 5.05 & 1.72 & Moller & 3 & 3.50 & 1.98 & 6.39 & 1.10 \\
\hline Gams & 1 & 1.61 & 0.92 & 6.32 & 1.33 & Moncel & 1 & 1.95 & 1.54 & 5.11 & 1.66 \\
\hline Garcia & 64 & 5.17 & 1.69 & 6.48 & 1.30 & Montieth & 1 & 1.84 & 1.44 & 4.59 & 1.97 \\
\hline
\end{tabular}


APPENDIX B (Continued)

\begin{tabular}{|c|c|c|c|c|c|c|c|c|c|c|c|}
\hline \multirow[b]{2}{*}{ Name } & \multirow[b]{2}{*}{ Frequency } & \multicolumn{2}{|c|}{ Familiarity } & \multicolumn{2}{|c|}{ Pronounceability } & \multirow[b]{2}{*}{ Name } & \multirow[b]{2}{*}{ Frequency } & \multicolumn{2}{|c|}{ Familiarity } & \multicolumn{2}{|c|}{ Pronounceability } \\
\hline & & $M$ & $S D$ & $M$ & $S D$ & & & $M$ & $S D$ & $M$ & $S D$ \\
\hline Moring & 2 & 2.16 & 1.47 & 6.20 & 1.07 & Skeslock & 1 & 1.50 & 0.88 & 4.07 & 2.04 \\
\hline Morrison & 31 & 5.48 & 1.30 & 6.84 & 0.53 & Sockrider & 1 & 1.84 & 1.34 & 6.39 & 1.08 \\
\hline Muccianti & 1 & 1.66 & 1.22 & 3.75 & 2.15 & Sola & 1 & 1.69 & 1.13 & 6.20 & 1.50 \\
\hline Mustapha & 2 & 2.43 & 1.86 & 5.18 & 1.79 & Solomon & 10 & 4.74 & 1.80 & 6.61 & 0.87 \\
\hline Nebel & 1 & 2.16 & 1.41 & 5.61 & 1.48 & Sorenson & 3 & 3.59 & 2.01 & 5.91 & 1.38 \\
\hline Nickel & 3 & 4.76 & 2.09 & 6.84 & 0.48 & Speece & 1 & 2.52 & 1.79 & 5.61 & 1.62 \\
\hline Ojeda & 1 & 2.05 & 1.74 & 3.93 & 2.02 & Spiewak & 3 & 1.62 & 1.32 & 4.34 & 1.75 \\
\hline Oler & 3 & 1.91 & 1.49 & 5.43 & 1.81 & Sriver & 2 & 2.38 & 1.73 & 4.73 & 2.04 \\
\hline Paule & 1 & 3.10 & 2.04 & 5.30 & 1.53 & Stegmann & 1 & 2.24 & 1.38 & 6.20 & 1.17 \\
\hline Perschon & 1 & 1.71 & 1.28 & 4.34 & 1.58 & Stoeck & 1 & 1.97 & 1.17 & 4.84 & 1.76 \\
\hline Philbrick & 1 & 1.93 & 1.21 & 5.77 & 1.54 & Sunny & 1 & 4.14 & 2.06 & 6.91 & 0.29 \\
\hline Pittenger & 3 & 1.88 & 1.24 & 5.32 & 1.60 & Surya & 1 & 1.34 & 0.69 & 4.45 & 1.81 \\
\hline Pizarro & 1 & 2.81 & 1.53 & 6.14 & 1.34 & Taborski & 1 & 1.60 & 0.94 & 5.30 & 1.86 \\
\hline Pounds & 2 & 4.36 & 2.19 & 6.91 & 0.47 & Taft & 1 & 4.45 & 1.67 & 6.82 & 0.45 \\
\hline Powley & 3 & 2.26 & 1.49 & 5.84 & 1.31 & Taliaferro & 1 & 1.28 & 0.81 & 3.80 & 1.81 \\
\hline Purchase & 1 & 4.12 & 2.30 & 6.80 & 0.70 & Timberlake & 3 & 2.93 & 1.92 & 6.75 & 0.72 \\
\hline Quackenbush & 2 & 2.10 & 1.72 & 5.89 & 1.37 & Timpanaro & 1 & 1.53 & 0.99 & 5.02 & 1.66 \\
\hline Rau & 4 & 1.83 & 1.43 & 4.66 & 1.66 & Tone & 1 & 3.76 & 2.27 & 6.84 & 0.48 \\
\hline Reidelbach & 3 & 2.10 & 1.35 & 5.14 & 1.61 & Tong & 15 & 2.48 & 1.76 & 6.73 & 0.97 \\
\hline Rhee & 2 & 1.74 & 1.18 & 5.43 & 1.74 & Tuerff & 1 & 1.21 & 0.45 & 3.95 & 1.80 \\
\hline Rhen & 1 & 1.91 & 1.45 & 5.55 & 1.53 & Tulley & 1 & 2.69 & 1.69 & 6.07 & 1.28 \\
\hline Roll & 2 & 3.95 & 2.23 & 6.82 & 0.84 & Udchitz & 1 & 1.33 & 0.96 & 2.89 & 1.63 \\
\hline Rozow & 1 & 1.43 & 0.92 & 5.09 & 1.60 & Updike & 3 & 2.50 & 1.81 & 6.34 & 1.20 \\
\hline Santogrossi & 1 & 1.84 & 1.32 & 4.20 & 1.92 & Vansanten & 1 & 1.67 & 1.18 & 4.89 & 1.53 \\
\hline Sarbacker & 1 & 1.66 & 1.05 & 5.41 & 1.30 & Viola & 1 & 3.66 & 2.01 & 6.23 & 1.34 \\
\hline Savabi & 2 & 1.17 & 0.53 & 4.02 & 1.72 & Whiting & 7 & 3.43 & 1.99 & 6.34 & 0.96 \\
\hline Schellenberg & 1 & 2.17 & 1.48 & 5.59 & 1.59 & Wilburn & 5 & 2.90 & 1.69 & 6.43 & 0.97 \\
\hline Schieffer & 1 & 3.72 & 2.03 & 5.80 & 1.44 & Wilks & 2 & 3.57 & 2.01 & 6.55 & 1.17 \\
\hline Schmidtke & 2 & 1.79 & 1.18 & 4.57 & 1.73 & Wissler & 1 & 2.88 & 1.87 & 6.05 & 1.24 \\
\hline Schoenhals & 2 & 1.45 & 1.01 & 3.45 & 1.68 & Wraight & 1 & 2.34 & 1.64 & 4.98 & 1.87 \\
\hline Segall & 1 & 4.28 & 1.98 & 6.48 & 1.02 & Wylie & 1 & 3.19 & 2.00 & 6.18 & 1.24 \\
\hline Selden & 1 & 2.55 & 1.50 & 6.23 & 1.27 & Yamokoski & 1 & 1.45 & 1.01 & 3.84 & 1.98 \\
\hline Semionov & 1 & 1.55 & 1.03 & 4.05 & 1.90 & Yeary & 1 & 1.69 & 1.16 & 5.55 & 1.59 \\
\hline Seufert & 4 & 2.10 & 1.75 & 4.34 & 1.63 & Yingling & 1 & 1.66 & 1.41 & 5.25 & 1.79 \\
\hline Shady & 1 & 3.41 & 2.07 & 6.82 & 0.54 & Yurkus & 1 & 1.50 & 1.06 & 4.86 & 1.82 \\
\hline Shahin & 1 & 1.29 & 0.59 & 3.80 & 1.84 & Zhang & 66 & 1.86 & 1.34 & 4.91 & 1.85 \\
\hline Shanbaky & 1 & 1.40 & 0.86 & 4.14 & 1.85 & Ziegler & 5 & 3.17 & 1.94 & 5.36 & 1.59 \\
\hline Shekh & 1 & 1.43 & 0.98 & 3.89 & 1.94 & & & & & & \\
\hline
\end{tabular}

(Manuscript received October 8, 1997;

revision accepted for publication July 15,1999 .) 